\title{
Species Authentication of Dog, Cat, and Tiger Using Cytochrome $\beta$ Gene
}

\author{
Irine $^{a, *}$, H. Nuraini ${ }^{b}$, \& C. Sumantri ${ }^{b}$ \\ ${ }^{a}$ Major Program of Animal Science Production and Technology, Graduate School, Bogor Agricultural University \\ ${ }^{b}$ Department of Animal Production and Technology, Faculty of Animal Science, Bogor Agricultural University \\ Jln. Agatis, Kampus IPB Darmaga, Bogor 16680, Indonesia \\ (Received 24-07-2013; Reviewed 23-09-2013; Accepted 19-12-2013)
}

\begin{abstract}
Adulteration of animal food products for economic reason has happened during the last decades. Species identification method development was needed to prevent falsification information. The objective of this research was to study species authentication (dog, cat, and tiger) to ensure animal origin in products using cyt $\beta$ gene specific marker. DNA extraction and fragment amplification were conducted using phenol-chloroform and multiplex PCR (Polymerase Chain Reaction) method, respectively. This research showed that fragment length of amplification for species tested (dog, cat, and tiger) were 523, 331, $319 \mathrm{bp}$, respectively. Species specificity was also indicated by high reverse primers homology percentage. Multiplex PCR technique succeed to amplify DNA fragment from species tested, but has a limitation to amplify total DNA composite of mix DNA.
\end{abstract}

Key words: cat, cytochrome $\beta$ gene, dog, multiplex PCR, tiger

\begin{abstract}
ABSTRAK
Upaya pemalsuan produk pangan asal ternak dengan alasan ekonomi masih sering terjadi hingga saat ini. Pengembangan metode identifikasi spesies diharapkan dapat melindungi konsumen dari pemalsuan informasi. Penelitian ini bertujuan untuk mempelajari pembuktian spesies anjing, kucing, dan harimau menggunakan marka spesifik berbasis gen sitokrom $\beta$ (cyt $\beta$ ). Ekstraksi DNA dilakukan dengan metode fenol-kloroform, semetara amplifikasi fragmen DNA menggunakan metode multipleks PCR. Penelitian ini menunjukkan bahwa amplifikasi panjang fragmen pada spesies anjing, kucing, dan harimau adalah 523, 568, dan 319 pb. Selain itu, kespesifikan spesies juga ditunjukkan dengan persentase homologi primer reverse yang tinggi pada masing-masing spesies. Metode multipleks PCR berhasil mengamplifikasi fragmen DNA dari semua spesies yang diuji, namun mempunyai keterbatasan dalam mengamplifikasi gabungan DNA total semua spesies.
\end{abstract}

Kata kunci: anjing, gen sitokrom $\beta$, harimau, kucing, multipleks PCR

\section{INTRODUCTION}

Today, many consumers are concerned by issues variety, such as food authenticity and adulteration (Aida et al., 2005; Ahmed et al., 2007; Abdel-Rahman et al., 2009). The identity of species origin in processed or composite mixture is not always readily apparent and accurate (Aida et al., 2005; Sakalar \& Abasiyanik, 2012). Consumers rarely can identify the species in product that they purchase: fresh or frozen cuts, and processed meat such as sausage, jerky, and canned foods (Hsieh et al., 2005; Ahmed et al., 2007). This opens fraudulent adulteration and substitution possibility of expected species with less costly value (Che Man et al., 2007; Rastogi et al.,

*Corresponding author:

E-mail: irenzpurple@yahoo.com
2007; Abdel-Rahman et al., 2009). To protect consumer rights, the legislation of each country should impose an accurate labelling declared the species to prevent food fraud (Ahmed, 2007; Abdel-Rahman et al., 2009; Ballin, 2010). The government has tried to protect consumers with the law (Law of the Republic Indonesia no. 8, 1999) and government regulation (Government Regulation no. 28,2004 , on safety, quality, and nutrition).

Most assays for species identification test only for husbandry species (Matsunaga et al., 1999; Hsieh et al., 2005; Martin et al., 2007a; Ahmed et al., 2007; Rastogi et al., 2007), and only a few reports for detection pet species in commercial materials (Ilhak \& Arslan, 2007; Martin et al., 2007b). Even though cat and dog are not commonly used, their presence in food products occasionally occurs (Martin et al., 2007b), such as the use of cat and dog meat in beef, lamb, and goat meat (Ilhak \& Arslan, 2007). 
Fraudulent substitution of alternative meat species in meat product needs a reliable and specific methods to determine the species.

Beside meat falsification, banned trade of endangered animals may still exist (Fajardo, 2010). Protected animal such as tiger is usually used as a component of medical product (Traditional Chinese Medicines) (Kitpipit et al., 2012; Wetton et al., 2004). This required supervision to prevent falsification information to consumer, along with increased market demand and high prices (Wetton et al., 2004).

Molecular technique development which can detect at DNA level are more accurate, although the samples had been processed. DNA sequence amplification from several species with a lot of primer (using same forward primer) in same reaction is one of the variation PCR (Polymerase Chain Reaction) called multiplex PCR (Matsunaga et al., 1999; Markoulatos et al., 2002; Jain et al., 2007). Matsunaga et al. (1999) using multiplex PCR to identify six meats (cattle, pig, chicken, sheep, goat, and horse) processed. Multiplex PCR could be used as a routine method with highly sensitive, rapid, simple, and not expensive to distinguish species (Jain et al., 2007). This research was to study species authentication (i.e. dog, cat, and tiger) to ensure animal origin in product using cyt $\beta$ gene specific marker and multiplex PCR. Thus, if specific reverse primers of cyt $\beta$ gene obtain, species identification will conduct at the same time for several species suspected.

Cyt $\beta$ gene is one of gene in mitochondrial DNA (mtDNA). mtDNA have multiple presences in cell (Minarovic et al., 2010). Cyt $\beta$ gene was used for species identification, but in 2003, cytochrome c oxidase subunit 1 (CO1) gene 'barcoding' was introduced for species identification and taxonomy. The size of cyt $\beta$ gene ranging from 1130 to $1149 \mathrm{bp}$ (Tobe et al., 2009) with average 1140 bp (Minarovic et al., 2010), and CO1 ranging from 1537 to $1557 \mathrm{bp}$ (Tobe et al., 2009). CO1 had more conserve area (43.7\% of $1557 \mathrm{bp})$ than cyt $\beta(22.4 \%$ of $1149 \mathrm{bp}$ ). Hence, for smaller fragment in mammalian samples, cyt $\beta$ gene will offer greater informative (Tobe et al., 2009).

\section{MATERIALS AND METHODS}

\section{Specific Primers}

Specific primers of cyt $\beta$ gene were used to amplify DNA fragment of goat, chicken, cattle, pig, and horse followed Matsunaga et al. (1999) method. DNA fragment amplification of sheep used a modified primer from Matsunaga et al. (1999), and rat primer followed the method of Nuraini et al. (2012). Forward primer used to amplify ten animals was same, and sequence of the primer as follows: 5'-GAC CTC CCA GCT CCA TCA AAC ATC TCA TCT TGA TGA AA-3' (Matsunaga et al., 1999). DNA sequances of dog (GenBank JF342903), cat (GenBank AB194817), and tiger (GenBank EU184702) were aligned using MEGA 5 software, furthermore specific reverse primers of cyt $\beta$ gene were designed manually (Table 1).

\section{DNA Extraction}

Blood samples (goat, chicken, cattle, sheep, horse, cat, rat), cooked meat samples (pig and dog), feces sample (tiger) were used for DNA extraction. Meat samples were used about $25 \mathrm{mg}$ and feces sample in $1 \times$ STE solution about $500 \mu \mathrm{L}$ Tiger feces normally contains some mucous. This mucous expected to contain epithelial tissue was kept in 1 x STE solution for DNA extraction process. DNA extraction process used phenolchloroform method (Sambrook \& Russel, 2001), included sample preparation, protein degradation, organic degradation, and DNA precipitation. Extraction process for meat and feces was started at protein degradation level. DNA concentration used for copying process in PCR was $50 \mu \mathrm{g} / \mathrm{mL}$. Using sample with same concentration conducted to equate amplification (Nuraini et al., 2012).

\section{DNA Genome Pool}

Genomics DNA from ten animals which each species containing $100 \mathrm{ng}$ were mixed in one tube. Furthermore, DNA sample from genome pool was taken $50 \mathrm{ng}$ and distributed on three tube, i.e tube 1 mixed with ten primers (goat, chicken, cattle, tiger, sheep, pig,

Table 1. Specific reverse primers of cyt $\beta$ gene

\begin{tabular}{|c|c|c|}
\hline Species & Reverse (5'-3') & PCR product length \\
\hline Goat $^{\mathrm{a}}$ & CTC GAC AAA TGT GAG TTA CAG AGG GA & $157 \mathrm{bp}$ \\
\hline Chicken $^{a}$ & AAG ATA CAG ATG AAG AAG AAT GAG GCG & $227 \mathrm{bp}$ \\
\hline Cattle $^{a}$ & CTA GAA AAG TGT AAG ACC CGT AAT ATA AG & $274 \mathrm{bp}$ \\
\hline Tiger & TAG CCA TGA CCG TAA ACA ATA GC & $319 \mathrm{bp}$ \\
\hline Sheep ${ }^{b}$ & CTA TGA ATG CTG TGG CTA TTG TCG CAA AT & $331 \mathrm{bp}$ \\
\hline Pig $^{a}$ & GCT GAT AGT AGA TTT GTG ATG ACC GTA & $398 \mathrm{bp}$ \\
\hline Horse $^{\mathrm{a}}$ & CTC AGA TTC ACT CGA CGA GGG TAG TA & 439 bp \\
\hline Dog & TTG CTA GAG CTG CGA TGA TGA AA & $523 \mathrm{bp}$ \\
\hline Cat & AGG GGT TGT TAG ATC CTG TTT CA & $568 \mathrm{bp}$ \\
\hline Rat $^{\mathrm{c}}$ & GAA TGG GAT TTT GTC TGC GTT GGA GTT T & $603 \mathrm{bp}$ \\
\hline
\end{tabular}

Note: a'Matsunaga et al. (1999); ${ }^{b}$ modified Matsunaga et al. (1999); 'Nuraini et al. (2012). 
horse, dog, cat, rat), tube 2 with five primers (goat, cattle, sheep, horse, cat), and tube 3 with five primers (chicken, tiger, pig, dog, rat).

\section{Specific DNA Fragments Amplification Using Multiplex PCR}

Specific DNA fragment amplification used PCR technique (polymerase chain reaction) with thermo cycler machine. PCR components used in total volume $15 \mu \mathrm{L}$ contained DNA sample (including DNA pool genome) $50 \mathrm{ng}$ genomic DNA and PCR reaction (i.e. distillate water $9 \mu \mathrm{L}$, forward primer 1.667 pmol, reverse primer 0.1667 pmol for each species, 1 x buffer reaction, dNTPs $0.267 \mathrm{mM}, \mathrm{MgCl} 21.667 \mathrm{mM}$, and enzyme taq fermentas 1 unit). PCR reaction had different component volume with five primers (i.e. distillate water $9.5 \mu \mathrm{L}$, forward primer $0.833 \mathrm{pmol}$, reverse primer $0.1667 \mathrm{pmol}$ for each species, 1 x buffer reaction, dNTPs $0.267 \mathrm{mM}$, $\mathrm{MgCl} 21.667 \mathrm{mM}$, and enzyme taq fermentas 1 unit). The condition of thermo cycler machine (Mastercycler Personal 22331, Eppendorf, Germany) consisted of predenaturation at $95^{\circ} \mathrm{C}$ for $5 \mathrm{~min}$, followed by 30 cycles of denaturation $95^{\circ} \mathrm{C}$ for $30 \mathrm{~s}$, annealing $60{ }^{\circ} \mathrm{C}$ for $45 \mathrm{~s}$, extension $72{ }^{\circ} \mathrm{C}$ for $1 \mathrm{~min}$, and the final extension step was at $72{ }^{\circ} \mathrm{C}$ for $5 \mathrm{~min}$.

\section{Electrophoresis}

PCR amplicons electrophoresis performed on $1.5 \%$ agarose gel and stained with EtBr (ethidium bromide) were visualized in UV transilluminator. Specific DNA fragment (goat, chicken, cattle, tiger, sheep, pig, horse, dog, cat, and rat) was analyzed by standard DNA size marker (100 bp).

\section{RESULTS AND DISCUSSION}

\section{Similarity Degree of $C y t \beta$ Gene Sequences}

Specific reverse primers homology percentage (Table 2) showed tracing reverse primers have a high homology percentage in one particular species and low in other species, so it could be used as a specific primer (Nuraini et al., 2012). Forward primer had high homology percentage about $84 \%-92 \%$ (38 nucleotides) among ten species, so it could be used as a general primer. Cyt $\beta$ gene has some stable sequences which were used for suggestion of universal primers and some variable sequences used for animal identification (Minarovic et al., 2010). Matsunaga et al. (1999) stated sheep primer mismatched with goat DNA only two nucleotides, however, 3 ' end mismatching was fatal for PCR amplification and resulted in no sheep band from goat template. In this research, only found one nucleotide mismatched with goat DNA (5'CTA TGA ATG CTG TGG CTA TTG TCG CA-3'), so sheep reverse primer was modified by adding three nucleotides in $3^{\prime}$ end (5'-CTA TGA ATG CTG TGG CTA TTG TCG CAA AT-3'). Attachment reverse primers at specific sequence of certain animal were caused by: 1) mismatched 3' end on each reverse primer (Matsunaga et al., 1999), 2) difference mismatched between reverse primers on every sequence DNA sample (about 9\%-45\%) resulted different melting temperature (Tm) (Viljoen et al., 2005).

\section{Specific Fragments Amplification of $C y t \beta$ Gene on Dog, Cat, and Tiger}

Primer specificity was tested in cooked dog meat, cat blood, and tiger feces. Processed product of cat meat was still rare, so cat meat sample was not used in this study, but DNA fragment of cat was amplified successfully from blood. Similarly with tiger sample was amplified successfully from feces. Electrophoresis DNA fragment of cyt $\beta$ gene amplification from dog, cat, and tiger was presented in Figure 1. Ilhak \& Arslan (2007) successfully to amplified cat and dog meat by adding $5 \%, 2.5 \%, 1 \%, 0.5 \%$, and $0.1 \%$ in beef, lamb, and goat meat. The number of PCR cycles used for amplification played an essential role in identification of meat in mixes $<0.5 \%$. PCR was conducted at 30 cycles for mixtures at the $5 \%, 2.5 \%, 1 \%, 0.5 \%$ level, while at 35 cycles for mixture at the $0.1 \%$ level (Ilhak \& Arslan,

Table 2. Specific reverse primers homology in ten animals

\begin{tabular}{|c|c|c|c|c|c|c|c|c|c|c|c|}
\hline \multirow[b]{2}{*}{ Specific primer } & \multicolumn{11}{|c|}{ \% Homology } \\
\hline & $\begin{array}{l}\text { Capra } \\
\text { hircus }\end{array}$ & $\begin{array}{l}\text { Gallus } \\
\text { gallus }\end{array}$ & $\begin{array}{c}\text { Bos } \\
\text { taurus }\end{array}$ & $\begin{array}{c}\text { Bos } \\
\text { indicus }\end{array}$ & $\begin{array}{c}\text { Panthera } \\
\text { tigris }\end{array}$ & $\begin{array}{l}\text { Ovis } \\
\text { aries }\end{array}$ & $\begin{array}{c}\text { Sus } \\
\text { scrofa }\end{array}$ & $\begin{array}{c}\text { Equus } \\
\text { caballus }\end{array}$ & $\begin{array}{l}\text { Canis } \\
\text { lupus }\end{array}$ & $\begin{array}{l}\text { Felis } \\
\text { catus }\end{array}$ & $\begin{array}{c}\text { Rattus } \\
\text { norvegicus }\end{array}$ \\
\hline Forward (38 nt) & 92,105 & 89,474 & 92,105 & 89,474 & 88,889 & 92,105 & 92,105 & 86,842 & 86,842 & 84,211 & 89,474 \\
\hline Goat (26 nt) & 96,154 & 65,385 & 73,077 & 73,077 & 69,231 & 84,615 & 73,077 & 73,077 & 73,077 & 73,077 & 69,231 \\
\hline Chicken (27 nt) & 70,370 & 100,000 & 62,963 & 62,963 & 70,370 & 66,667 & 62,963 & 70,370 & 70,370 & 62,963 & 77,778 \\
\hline Cattle (29 nt) & 72,414 & 62,069 & 100,000 & 100,000 & 68,966 & 75,862 & 72,414 & 79,310 & 68,966 & 68,966 & 75,862 \\
\hline Tiger (23 nt) & 56,522 & 56,522 & 60,870 & 60,870 & 100,000 & 56,522 & 69,565 & 69,565 & 60,870 & 78,261 & 69,565 \\
\hline Sheep (29 nt) & 86,207 & 55,172 & 72,414 & 72,414 & 72,414 & 100,000 & 75,862 & 68,966 & 86,207 & 72,414 & 75,862 \\
\hline Pig (27 nt) & 81,481 & 77,778 & 77,778 & 77,778 & - & 70,370 & 100,000 & 81,481 & 74,074 & 74,074 & 81,481 \\
\hline Horse (26 nt) & 80,769 & 69,231 & 73,077 & 73,077 & - & 80,769 & 76,923 & 100,000 & 69,231 & 69,231 & 88,462 \\
\hline Dog (23 nt) & 78,261 & 56,522 & 65,217 & 65,217 & - & 82,609 & 69,565 & 73,913 & 100,000 & 73,913 & 78,261 \\
\hline Cat (23 nt) & 86,957 & 78,261 & 78,261 & 78,261 & - & 86,957 & 78,261 & 91,304 & 82,609 & 100,000 & 82,609 \\
\hline Rat (28 nt) & 71,429 & 67,857 & 78,571 & 78,571 & - & 64,286 & 64,286 & 67,857 & 71,429 & 78,571 & 96,429 \\
\hline
\end{tabular}




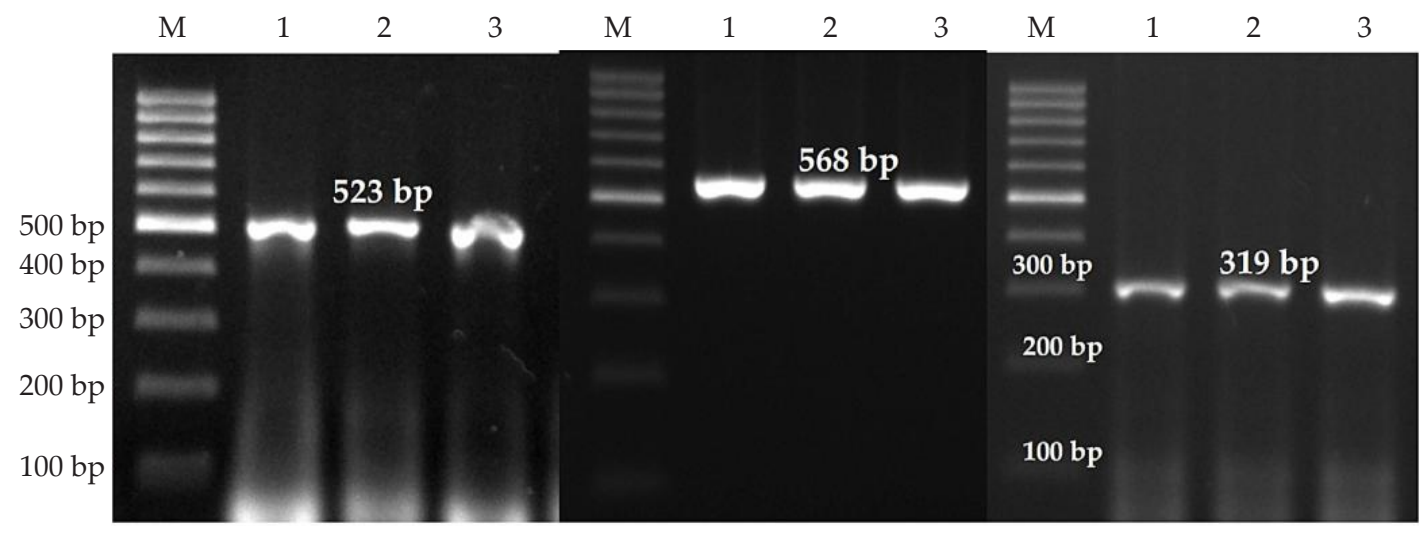

(a) $\operatorname{dog}$ (meat)

(b) cat (blood)

(c) tiger (feces)

Figure 1. Specific fragments amplification on dog, cat, and tiger. M: marker 100 bp, (1) (2) (3): sample replication.

2007). Owing to the potential for degradation of samples found in a forensic context, nuclear DNA is unlikely to yield results, therefore, mitochondrial DNA maybe used an alternative means of species identification (Kitpipit et al., 2012). Species identification of tiger and cat had been distinguished at the genus level using specific reverse primers.

\section{Specific Fragments Amplification of $C y t \beta$ Gene on Dog, Cat, and Tiger}

Reverse primers of $c y t \beta$ gene successfully to amplified DNA fragment of ten animals with different length fragment. The amplification fragment length of goat, chicken, cattle, sheep, pig, horse were 157, 227, 274, 331, 398, and 439 bp, respectively (Matsunaga et al., 1999), and fragment rat was $603 \mathrm{bp}$ (Nuraini et al., 2012), while tiger, dog, and cat amplified were 319, 523, $568 \mathrm{bp}$, respectively (Figure 2). Ampilification target sequences from several species simultaneously (using the same forward primer) including more than one pair of primers in the same reaction is a variant of PCR called Multiplex PCR (Matsunaga et al., 1999; Markoulatos et al., 2002; Jain et al., 2007). Electrophoresis specific DNA fragment of cyt $\beta$ gene was presented in Figure 3. Minarovic et al. (2010) successfully to identify species using PCRRFLP with same primer for all species (i.e. Mustela vison (American mink), Mustela putorius furo (Ferret), Sus scrofa domesticus (pig), Oryctolagus cuniculus (Rabbit)), which were designed by Kocher et al. (1989). PCR products length did not different for all species, $359 \mathrm{bp}$, furthermore were cleaved by restriction enzyme AluI. Every animal has a unique combination of restriction fragments (Minarovic et al., 2010). Species determination by PCR was affected by cooking temperature, time, and size of the DNA fragment to be amplified (Martinez \& Yman, 1998; Matsunaga et al., 1999; Arslan et al., 2006).

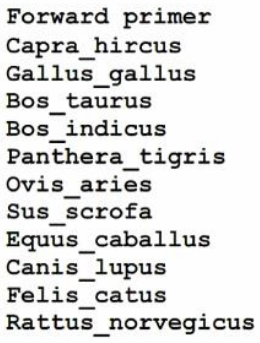

Capra_hircus Gallus_gallus Bos_taurus Bos indicus Panthera tigris ovis_ariēs Sus_scrofa Equus caballus Canis lupus Felis catus Rattus_norvegicus

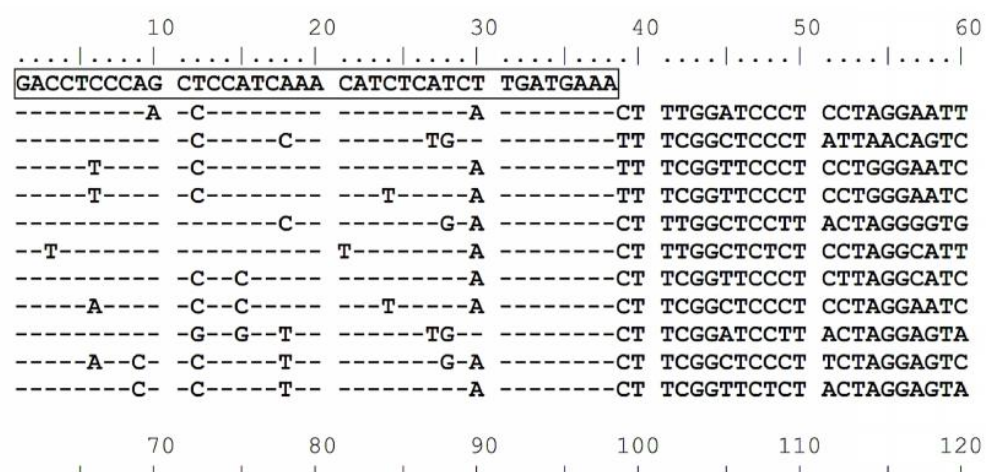

TGCCTAATCT TACAAATCCT GACAGGCCTA TTCCTAGCAA TACACTATAC АTCCGACACA TGCCTCATGA CCCAAATCCT CACCGGCCTA CTACTAGCCA TGCACTACAC AGCAGACACA TGCCTAATCC TACAAATCCT CACAGGCCTA TTCCTAGCAA TACACTACAC ATCCGACACA TGCCTAATCC TACAAATCCT CACAGGCCTA TTCCTAGCAA TACACTACAC ATCCGACACA TGCTTAATCT TACAAATCCT CACTGGCCTC TTTCTAGCCA TACACTACAC ATCAGACACA TGCTTAATTT TACAGATCCT AACAGGCCTA TTCCTAGCAA TACACTATAC ACCTGACACA TGCCTAATCT TGCAAATCCT AACAGGCCTG TTCTTAGCAA TACATTACAC ATCAGACACA TGCCTAATCC TCCAAATCTT AACAGGCCTA TTCCTAGCCA TACACTACAC ATCAGACACG TGCTTGATTC TACAGATTCT AACAGGTTTA TTCTTAGCTA TGCACTATAC ATCGGACACA TGCCTAATCT TACAAATCCT CACCGGCCTC TTTTTGGCCA TACACTACAC ATCAGACACA TGCCTCATAG TACAAATCCT CACAGGCTTA TTCCTAGCAA TACACTACAC GTCTGATACC 
Capra_hircus Gallus gallus Bos_taurus Bos indicus Panthera_tigris ovis aries Sus scrofa Equús_caballus Canis_lupus Felis_catus Rattus norvegicus

Capra_hircus Gallus gallus Bos_taurus Bos_indicus Panthera_tigris Ovis_aries Sus scrofa Equús_caballus Canis_lupus Felis catus Rattus norvegicus

Capra hircus Gallus gallus Bos taurus Bos indicus Panthera tigris Ovis aries Sus_scrofa Equús_caballus Canis lupus Felis catus Rattus_norvegicus Primer_Panthera

Capra hircus Gallus_gallus Bos_taūrus Bos indicus Panthera tigris Ovis_aries Sus_scrofa Equūs_caballus Canis lupus Felis_catus Rattus_norvegicus Primer_Panthera

Capra_hircus Gallus gallus Bos_taurus Bos indicus Panthera_tigris ovis_ariē Sus scrofa Equus caballus Canis_lupus Felis catus Rattus norvegicus

Capra_hircus Gallus gallus Bos taurus Bos_indicus Panthera_tigris ovis aries Sus scrofa Equús_caballus Canis_lupus Felis catus Rattus norvegicus

130

150

160

170

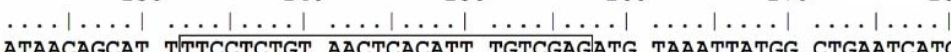
ATAACAGCAT TTTCCTCTGT AACTCACATT TGTCGAGATG TAAATTATGG CTGAATCATC TCCCTAGCCT TC----C-- -G-C---C- --C--GAACG TACAATACGG CTGACTCATC ACAACAGCAT TC------- T--C--T--C --C----ACG TGAACTACGG CTGAATCATC ACAACAGCAT TC------- T--C--T--C --C----ACG TGAACTACGG CTGAATCATC ATAACCGCTT TC--A--A-- T--C------ --C--C-ACG TAAACTACGG TTGGATTATC ACAACAGCAT TC------ ---C----- --C---ACG TAAACTATGG CTGAATTATC ACAACAGCTT TC--A--A-- T--A-----C -----ACG TAAATTACGG ATGAGTTATT ACAACTGCCT TC--A--C-- C--------C --C----ACG TTAACTACGG ATGAATTATT GCCACAGCTT T---A--A-- C--C-----C --C----ACG TTAACTACGG CTGAATTATC ATAACCGCCT T---A--A-- T--C-----C ----C-ACG TTAATTATGG CTGAATCATC ATAACAGCAT TC--A--A-- C--C-----C --C----ACG TAAACTACGG CTGACTAATC

$$
190
$$$$
200
$$

210

220

230

240

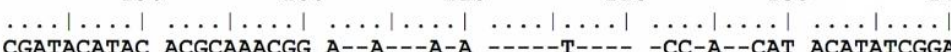
CGATACATAC ACGCAAACG A--A---A-A $-\cdots,-1-\cdots,-$ CC-A--CAT ACATATCGGA CGGAATCTCC ACGCAAACG CGCCTCATTC TTCTTCATCT GTATCTTCCT TCACATCGGA CGATACATAC ACGCAAACG A--T---A-G --T--T---- -CT-A-ATAT GCACGTAGGA CGATACATAC ACGCAAACGG A--T---A-G --T--T---- -CT-A-ATAT GCACGTAGGA CGATATCTAC ATGCCAACG A----CA-A ----T--- --C-A-ACAT GCACGTAGGA CGATACATAC ACGCAAACGG A--A---A-A --T--T---- -CC-A--TAT GCATGTAGGA CGCTACCTAC ATGCAAACGG A--A--CA-G ----T--T- -CC-A--CAT CCACGTAGGC CGCTACCTCC ATGCCAACGG A--A---A-A --T--T---- -CC----CAT TCACGTAGGA CGCTATATGC ACGCAAATGG ---T--CA-A -----T--- -CC-A--CCT ACATGTAGGA CGATATTTAC ACGCCAACGG A--T--TA-A ----T---- -CC-G-ACAT ACATGTAGGA CGATACCTAC ACGCCAACGG -------A-A --T------ -CC-A--CCT CCATGTGGGA

$$
250
$$$$
260
$$

270 280 290 $\ldots \ldots|\ldots| \ldots|\ldots| \ldots|\ldots| \ldots|\ldots| \ldots|\ldots| \ldots|\ldots| \ldots|\ldots| \ldots|\ldots|$ CGAGG-C--- -C-----C-- C---CTC-A- AAG-AAACCT GAAACACAGG AGTAATC--C CGAGG CTTAT ATTACGGGTC TTACACTTTT CTAGAAACAT GAAATATTGG AGTAATC--T CGAGGCTTAT ATTACGGGTC TTACACTTTT CTAGAAACAT GAAATATTGG AGTAATC--T CGAGGAA--- -C-----C-- C-----C--C TC--AAACAT GAAATATCGG GATTGT GCTA CGAGG-C--- ----T--A-- A--T--C--C ----AAACAT GAAACATCGG AGTAATC--C CGAGG-C--- -C-----A-- C--T-TA--C ----AAACAT GAAACATTGG AGTAGTC--CGCGG-C-C- -C-----C-- -----A--C ----AGACAT GAAACATTGG AATCATC--CGAGG-C--- ------A-- C--TGTA--C A---AAACAT GAAACATTGG AATTGTA--CGGGGAA--- - C-----C-- C-----C--C TC--AGACAT GAAACATTGG AATCATA--CGAGGAC--- -C--T--A-- C-------C --- AAACCT GAAACATTGG GATCATC---

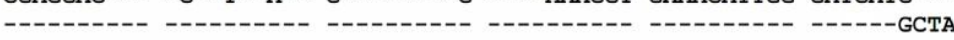

$$
\begin{array}{llllll}
310 & 320 & 330 & 340 & 350 & 360
\end{array}
$$
$\ldots \ldots|\ldots| \ldots|\ldots| \ldots|\ldots| \ldots|\ldots| \ldots|\ldots| \ldots|\ldots| \ldots|\ldots| \ldots|\ldots| \ldots \mid$ CTCC-C--AC ----*--*-- C--C--TG-G -GCTATGTTC TCCCATGGGG CCAAATATCA CT-C-C--A- $-\star--*--\star-------T---$-GATACGTCC TACCATGAGG ACAAATATCA CT-C-C--A- - $--\star--*-------T---$-GATACGTCC TACCATGAGG ACAAATATCA -T---- - - - - - - - ---C----- -GATATGTCT TACCATGAGG ACAAATATCA CT ATTTGCGA CAATAGCCAC AGCATTCATA GGCTATGTTT TACCATGAgG ACAAATATCA CT*-----C- -T--*--A-- ---C------ -GCTACGTCC TGCCCTGAGG ACAAATATCA CTT--C--A- -T--*----- -------G -GCTATGTCC TACCATGAGG CCAAATATCC $-T^{\star}--C *-A * \star---\star--*---------G$-GCTATGTAC TACCATGAGG ACAAATATCA

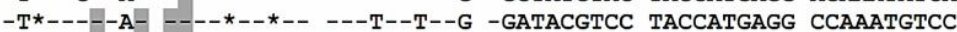
CT*---*-ATTGTTTACGG TCATGGCTA- -

380

390

400

410

420

$\ldots|\ldots| \ldots|\ldots| \ldots|\ldots| \ldots|\ldots| \ldots|\ldots| \ldots|\ldots| \ldots|\ldots|$ TTTTGAGGG CA--A------T---T --T---AA TCCCATATAT TGGC--A-ATTCTGAGGGG CC--C--T-- -----C--- T-C-----AA TTCCCTACAT TGGACAC--TTCTGAGGAG CA--A----- ---C--C--C T------AA TCCCATACAT CGGC--A-AT TTCTGAGGAG CA--A----- ---C--C--C T------AA TCCCATACAT CGGC--A-AT TTCTGAGGG CA--.-TTCTGAGGAG CA--A--T-- T--C--C--C --T-----AA TTCCATATGT TGGC--A-ATTCTGAGGAG CTACGGTCAT CACAAATCTA CTATCAGCTA TCCCTTATAT CGGA--AGATTTTGAGGAG CA--A---- ---G--C--C------AA TTCCCTACAT CGGTACTACC TTTTGAGGAG CA--T--A-- ---T-----T --C--T--CA TCCCTTATAT CGGA---GATTCTGAGGAG CA--C--A-- ---T--C--C --G-----AA TTCCATACAT CGGG---GAA TTCTGAGGAG C---A--A-- T-----C--- T------TA TCCCTTACAT TGGG------

$\ldots|\ldots| \ldots|\ldots| \ldots|\ldots| \ldots|\ldots| \ldots|\ldots| \ldots|\ldots| \ldots|\ldots| \ldots|\ldots|$

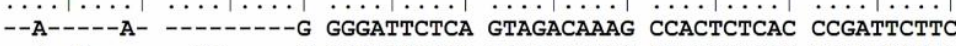
--A--A---- --GC-----G GGGATTTTCA GTCGACAACC CAACCCTTAC CCGATTCTTC T-A-----A- -------G CGGATTCTCA GTAGACAAAG CAACCCTTAC CCGATTCTTC T-A----A- ------G CGGATTCTCA GTAGACAAAG CAACCCTTAC CCGATTCTTC - A-- A- ----A--A- --------G GGGCTTTTCC GTCGACAAAG CAACCCTCAC ACGATTCTTC CTCGTCGAGT GAATCTGAG TGGATTCTCA GTAGACAAAG CCACCCTTAC CCGATTTTTT T-A--A--A- -G------G CGGCTTCTCA GTGGACAAAG CAACCCTAAC ACGATTCTTT $--A--A--A--$ G-------G GGGCTTCTCA GTAGACAAAG CCACCCTAAC ACGATTCTTC -- A-----A- --------G AGGCTTCTCA GTAGACAAAG CAACCCTAAC ACGCTTCTTC

Continued 


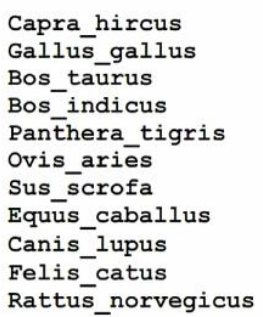

Primer

Capra_hircus Gallus gallus Bos_taurus

Bos indicus Panthera_tigris ovis_ariēs Sus scrofa Equus caballus Canis_lupus Felis_catus Rattus norvegicus

Capra_hircus Gallus_gallus

Bos_taurus Bos indicus Panthera_tigris Ovis_aries Sus scrofa Equus caballus Canis_lupus Felis_catus Rattus_norvegicus

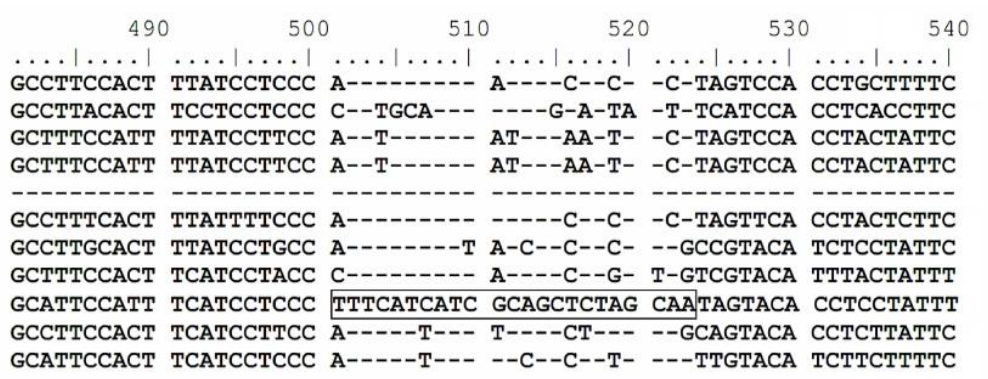

$$
\begin{aligned}
& \begin{array}{rrrrr}
550 & 560 & 570 & 580 & 590
\end{array} \\
& \ldots|\ldots| \ldots|\ldots| \ldots|\ldots| \ldots|\ldots| \ldots|\ldots| \ldots|\ldots| \ldots|\ldots| \ldots|\ldots|
\end{aligned}
$$

Figure 2. Primer sequences and target region on cytochrome $\beta$ gene (boxes: forward and specific reverse primers, dash: identical nucleotides with primer sequence, open boxes and dash: identical nucleotides with tiger sequence, star symbol: identical nucleotides with sheep sequence.

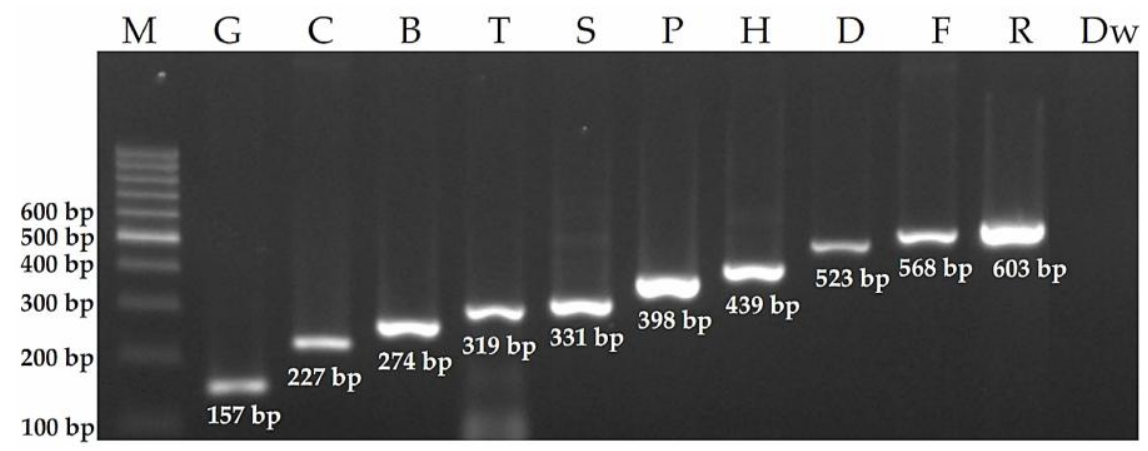

Figure 3. Specific fragments amplification on several animal. M: marker 100 bp, G: goat, C: chicken, B: cattle, T: tiger, S: sheep, P: pig, H: horse, D: dog, F: cat, R: rat, Dw: negative control.

\section{Specific Fragments Amplification of $C y t \beta$ Gene on DNA Genome Pool}

This research showed only six bands in tube 1 (i.e. goat, chicken, cattle, tiger, pig, cat) were amplified successfully at DNA mix from ten species (Figure 4). It was probably caused band overlapped between tiger (319 bp) and sheep (331 bp); dog (523 bp), cat (568 bp), and rat (603 bp), because they have adjacent fragment length. Large molecules migrate more slowly than smaller mol- ecules (Sambrook \& Russel, 2001). To ensure this, the test was carried out by separating overlapped band and adjacent fragment length. Tube 2 had five bands (goat, cattle, sheep, horse, cat), but tube 3 only had four bands (chicken, tiger, pig, rat) and no dog band (Figure 4). In general, quantitative PCR is difficult because of unequal efficiency of amplication. Amplification efficiency is affected by the difference primer sequences (Matsunaga et al., 1999). 


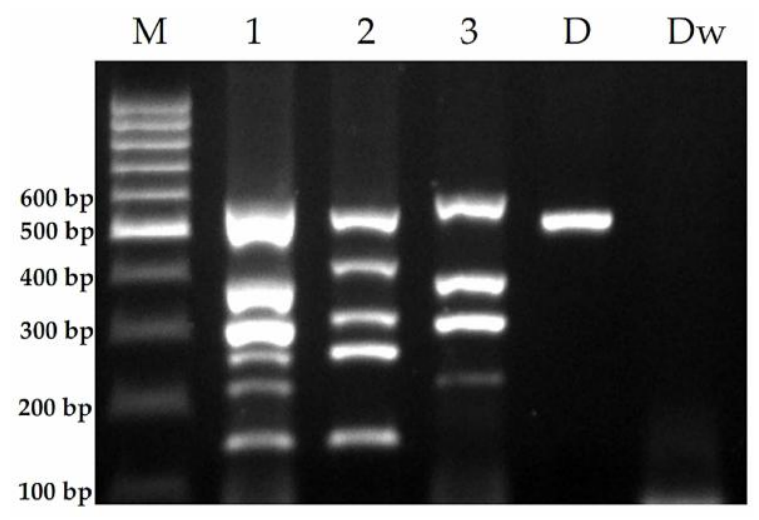

Figure 4. Specific fragments amplification on genome pool. M: marker $100 \mathrm{bp}, 1$ : tube 1 (goat, chicken, cattle, tiger, pig, cat), 2: tube 2 (goat, cattle, sheep, horse, cat), 3: tube 3 (chicken, tiger, pig, rat), D: dog, Dw: negative control.

\section{CONCLUSION}

Dog, cat, and tiger DNA are amplified successfully with fragment length of 523, 568, $319 \mathrm{bp}$, respectively. Species specifity of dog, cat, and tiger are indicated by high reverse primers homology persentage. Multiplex PCR technique success to amplify DNA fragment from species tested, but has a limitation to amplify total DNA composite of mix DNA.

\section{ACKNOWLEDGMENT}

Authors would like to thank Prof. drh. Dondin Sajuthi, MST, PhD. and Dr. drh. Ligaya I.T.A. Tumbelaka, SpMp, MSc. for tiger sample. This research was supported by Indonesia Endowment Fund For Education (Lembaga Pengelola Dana Pendidikan); Research and Community Services Institution, Bogor Agricultural University (LPPM IPB) through a competitive grant project (Hibah Bersaing) with contract no. 56/IT3.41.2/L1/SPK/2013.

\section{REFERENCES}

Abdel-Rahman, S. M., M. A. El-Saadani, K. M. Ashry, \& A. S. Haggag. 2009. Detection of adulteration and identification of cat's, dog's, donkey's and horse's meat using species-specific PCR and PCR-RFLP Techniques. Aust. J. Basic Appl. Sci. 3:1716-1719.

Ahmed, M. M. M., S. M. Abdel-Rahman., \& A. A. El-Hanafy. 2007. Application of species-specific polymerase chain reaction and cytochrome $b$ gene for different meat species authentication. Biotechnol. 6:426-430. http://dx.doi. org/10.3923/biotech.2007.426.430

Aida, A. A., Y. B. Che Man, C. M. V. L. Wong, A. R. Raha, \& R. Son. 2005. Analysis of raw meats and fat of pigs using polymerase chain reaction for Halal authentication. Meat Sci. 69:47-52. http://dx.doi.org/10.1016/j.meatsci.2004.06.020

Arslan, A., O. I. Ilhak, \& M. Calicioglu. 2006. Effect of method of cooking on identification of heat processed beef using polymerase chain reaction (PCR) technique. Meat Sci. 72:326-330. http://dx.doi.org/10.1016/j.meatsci.2005.08.001

Ballin, N. Z. 2010. Authentication of meat and meat products: Review. Meat Sci.86: 577-587. http://dx.doi.org/10.1016/ j.meatsci.2010.06.001

Che Man, Y. B., A. A. Aida, A.R. Raha, \& R. Son. 2007. Identification of pork derivatives in food products by species-specific polymerase chain reaction (PCR) for halal verification. Food Control. 18:885-889. http://dx.doi. org/10.1016/j.foodcont.2006.05.004

Fajarado, V., I. Gonzalez, M. Rojas, T. Garcia, \& R. Martin. 2010. A review of current PCR-based methodologies for the authentication of meats from game animal species. Trends Food Sci. Technol. 21:408-421. http://dx.doi.org/10.1016/ j.tifs.2010.06.002

Government Regulation Republic of Indonesia Number 28 . 2004. Safety, quality, dan nutrition. State Gazette of Republic of Indonesia in 2004 Number 107.

Hsieh, H. M., C. C. Tsai, L. C. Tsai, H. L. Chiang, N. E. Huang, R. T. P. Shih, A. Linacre, \& J. C. I Lee. 2005. Species identification of meat products using the cytochrome $\mathrm{b}$ gene. Forensic Sci. J. 4: 29-36.

Ilhak, O. I. \& A. Arslan. 2007. Identification of meat species by polymerase chain reaction (PCR) technique. Turk. J. Vet. Anim. Sci. 31:159-163.

Jain, S., M. N. Brahmbhati, D. N. Rank, C. G. Joshi, \& J. V. Solank. 2007. Use of cytochrome b gene variability in detecting meat species by multiplex PCR assay. Indian J. Anim. Sci. 77: 880-881.

Kitpipit, T., S. S. Tobe, A. C. Kitchener, P. Gill, \& A. Linacre. 2012. The development and validation of a single SNaPshot multiplex for tiger species and subspecies identification-Implications for forensic purposes. Forensic Sci. Int. 6: 250-257. http://dx.doi.org/10.1016/j.fsigen.2011.06.001

Kocher, T. D., W. K. Thomas, A. Meyer, S. V. Edwards, S. Paabo, F. X. Villablanca, \& A. C. Wilson. 1989. Dynamics of mitochondrial DNA evolution in animals: Amplification and sequencing with conserved primers. Proc. Natl. Acad. Sci. USA. 86: 6196-6200.\& N. Species-specific PCR for the identification of ovine, porcine, and chicken species in meat and bone meal (MBM). Mol Cellular Probes. 15:2735. http://dx.doi.org/10.1006/mcpr.2000.0336

Law of the Republic Indonesia Number 8. 1999. Consumer Protection. State Gazette of Republic of Indonesia in 1999 Number 42.

Markoulatos P., N. Siafakas, \& M. Moncany. 2002. Multiplex polymerase chain reaction: a practical approach. J. Clinical Laboratory Analysis. 16:47-51. http://dx.doi.org/10.1002/ jcla.2058

Martin, I., T. Garcia, V. Fajardo, I. Lopez-Calleja, M. Rojas, P. E. Hernandez, I. Gonzalez, \& R. Martin. 2007a. Mitochondrial markers for the detection of four duck species and the specific identification of Muscovy duck in meat mixtures using the polymerase chain reaction. Meat Sci. 76: 721-729. http://dx.doi.org/10.1016/j.meatsci.2007.02.013.

Martin, I., T. Garcia, V. Fajardo, M. Rojas, P. E. Hernandez, I. Gonzalez, \& R. Martin. 2007b. Technical Note: detection of cat, dog, and rat or mouse tissues in food and animal feed using species-specific polymerase chain reaction. J. Anim. Sci. 85:2734-2739. http://dx.doi.org/10.2527/jas.20070048

Martinez, I. \& I. M. Yman. 1998. Species identification in meat products by RAPD analysis. Food Res. Int. 31:459-466. http://dx.doi.org/10.1016/S0963-9969(99)00013-7

Matsunaga, T., K. Chikuni, R. Tanabe, S.Muroya, K. Shibata, J. Yamada, \& Y. Shinmura. 1999. A quick and simple method for the identification of meat species and meat products by PCR assay. Meat Sci. 51:143-148. http://dx.doi.org/10.1016/ S0309-1740(98)00112-0

Minarovic, T., A. Trakovicka, A. Rafayova, \& Z. Lieskovska. 2010. Animal species identification by PCR-RFLP of cytochrome b. Scientific Paper: Anim. Sci. Biotechnol. 43:296299. 
Nuraini, H., A. Primasari, E. Andreas, \& C. Sumantri. 2012. The use of cytochrome b gene as a specific marker of the rat meat (Rattus norvegicus) on meat and meat products. Med. Pet. 35:15-20. http://dx.doi.org/10.5398/medpet.2012.35.1.15

Rastogi, G., M. S. Dharne, S. Walujkar, A. Kumar, M. S. Patole, \& Y. S. Shouche. 2007. Species identification and authentication of tissues of animal origin using mitochondrial and nuclear markers. Meat Sci. 76:666-674. http://dx.doi. org/10.1016/j.meatsci.2007.02.006

Sakalar, E., \& M. F. Abasiyanik. 2012. The development of duplex real-time PCR based on SYBR Green florescence for rapid identification of ruminant and poultry origins in foodstuff. Food Chem. 130: 1050-1054. http://dx.doi. org/10.1016/j.foodchem.2011.07.130.
Sambrook, J. \& D. Russel. 2001. Molecular Cloning a Laboiratory Manual. Ed ke-3. CSH Laboratory Press, United State of America (US).

Tobe, S. S., A. Kitchener, \& A. Linacre. 2009. Cytochrome b or cytochrome c oxidase subunit 1 for mammalian species identification-An answer to the debate. Forensic Sci. Int.: Genetics Supplement Series 2:306-307. http://dx.doi. org/10.1016/j.fsigss.2009.08.053

Viljoen, G. J., L. H. Nel, \& J. R. Crowther. 2005. Molecular Diagnostic PCR Handbook. Netherlands (NL): Springer.

Wetton, J. H., C. S. F. Tsang, C. A. Roney, \& A. C. Spriggs. 2004. An extremely sensitive species-specific ARMs PCR test for the presence of tiger bone DNA. Forensic Sci. Int. 140:139145. http://dx.doi.org/10.1016/j.forsciint.2003.11.018 